\title{
Interaction between the gut microbiome and mucosal immune system
}

$\mathrm{Na} \mathrm{Shi}{ }^{1 \dagger}, \mathrm{Na} \mathrm{Li}^{2+}$, Xinwang Duan ${ }^{2}$ and Haitao Niu ${ }^{1 *}$

\begin{abstract}
The gut microbiota, the largest symbiotic ecosystem with the host, has been shown to play important roles in maintaining intestinal homeostasis. Dysbiosis of the gut microbiome is caused by the imbalance between the commensal and pathogenic microbiomes. The commensal microbiome regulates the maturation of the mucosal immune system, while the pathogenic microbiome causes immunity dysfunction, resulting in disease development. The gut mucosal immune system, which consists of lymph nodes, lamina propria and epithelial cells, constitutes a protective barrier for the integrity of the intestinal tract. The composition of the gut microbiota is under the surveillance of the normal mucosal immune system. Inflammation, which is caused by abnormal immune responses, influences the balance of the gut microbiome, resulting in intestinal diseases. In this review, we briefly outlined the interaction between the gut microbiota and the immune system and provided a reference for future studies.
\end{abstract}

Keywords: Microbiome, Immunity, Inflammation

\section{Background}

The mammalian gut contains a microbial community, defined as the microbiome, which includes bacteria, viruses, fungi, etc. Microbial genome sequences contain $3 \times 10^{6}$ genes, which is approximately 150 -fold the length of the human genome [1]. In recent decades, next generation sequencing technology has contributed to understanding the intricate relationship between the microbiome and related diseases. 16S rRNA sequencing results showed that Firmicutes and Bacteroidetes make up approximately $92 \%$ of the human microbiome [2]. Gut microbiota include 1,000 to 1,500 bacterial species; however, an individual contains only approximately 160 bacterial species, indicating that the composition of the microbiome is substantially different between individuals and is related to environmental changes and genetic inheritance $[3,4]$. Environmental factors play a very important role in the gut microbiome. Even mice with the same genotype housed in separate cages within the same

\footnotetext{
* Correspondence: htniu1@yahoo.com

${ }^{\dagger}$ Equal contributors

${ }^{1}$ Institute of Laboratory Animal Sciences, Chinese Academy of Medical Sciences (CAMS) and Comparative Medicine Center, Peking Union Medical Collage (PUMC), Key Laboratory of Human Disease Comparative Medicine, Ministry of Health, Beijing 100021, China

Full list of author information is available at the end of the article
}

facility show different microbiota compositions [5]. The composition of the mouse gut microbiome is mainly influenced by variations in diet, age and inflammation $[5,6]$. A review of studies also showed that the composition of the gut microbiome in an eczema population is influenced by environmental factors, including pregnancy duration, delivery method, feeding type, rearing style, number of siblings, lifestyle, etc. [7]. The intestinal microbiome, a microbial organ that is shaped in combination with the host's genotype, responds to the growth process and environmental exposure. The coordinated interactions between intestinal microbial populations contribute to maintaining intestinal homeostasis and play an important role in the immune process.

The symbiotic relationship between microbiota and the host is mutually beneficial. The host provides an important habitat and nutrients for the microbiome, and the gut microbiota support the development of the metabolic system and the maturation of the intestinal immune system by providing beneficial nutrients, e.g., by the synthesis of vitamins [8] and short chain fatty acids (SCFAs) $[9,10]$. Therefore, the interaction between the microbiome and intestinal immune system is critical to maintain mucosal homeostasis. However, when the balanced gut microbial communities change, dysbiosis 
causes intestinal diseases [11]. Microbial colonization depends on the development of the immune system. The rapid colonization of microbiota in the neonatal gastrointestinal tract plays a vital role in the development of the gut immune system [12]. However, studies in Germ-Free (GF) animals revealed that the lack of gut microbiota caused a significant immune system deficiency. Furthermore, the dysbiosis of gut microbiota has been closely linked to several diseases, such as obesity [13], type 2 diabetes [14], hypertension [15], necrotizing enterocolitis (NEC) [16], and inflammatory bowel diseases(IBD) [17], etc.

The aim of this review is to briefly summarize the interaction between the gut microbiome and mucosal immune system, as well as the development of autoimmune diseases.

\section{The intestinal mucosal immune system}

The immune system is regulated by immune organs, immune cells, soluble cytokines and cell receptors. The intestine mucosal immune system consists of three different mucosal lymphoid structures: Peyer's patches, the lamina propria and the epithelia [6].

The mucus layer on the surface of epithelial cells is the first line of defense in the organism's physiological barrier. In the small intestine epithelia, Paneth cells located at the base of crypts are capable of secreting antimicrobial peptides (AMPs) in response to bacteria or pathogens in the gut lumen and contribute to intestinal innate host defense [18]. The AMPs include $\alpha$-defensins (HD5 and HD6 in humans and cryptdins in mice), RegIII and lysozymes, etc. [19]. The mucus layer and AMPs constitute the mucosal barrier to prevent the invasion of symbiotic bacteria. Pioneering studies have discovered an important role for AMPs in the host mucosal defense, indicating that they directly affect the microbiome in the intestinal lumen [20-22]. AMPs can exert antimicrobial activities to kill microorganisms in vitro [18]. RegIII specifically targets Gram-positive bacteria. Additionally, bacteria and bacterial antigens increased the expression of RegIII $\gamma$ [23], cryptdin [24], and human $\beta$-defensin 2 [25]. Moreover, RegIII $\beta$ was significantly increased, and it was released into the gut lumen in response to infection [26]. RegIII segregating the bacteria from the intestinal epithelium, and the absence of RegIII $\gamma$ led to increased bacteria colonization on the epithelium and the activation of adaptive immunity [27].

Epithelial cells are the second physical barrier of the intestinal mucosal immune system, and they directly participate in the immune surveillance of the gut. Epithelial cells are not only involved in the direct defense of microorganisms; they also send signals to the mucosal immune system by producing cytokines and chemokines
[11]. In response to stimuli, a class of innate lymphoid cells (ILCs) located in the epithelial cells can be activated to produce cytokines, which play a defensive or a pathogenic role in inflammation; this response is closely related to the control of intestinal homeostasis in mammals. IL22 is produced by ILCs and promotes homeostasis and healing during infection in the gut $[28,29]$. IL-22 is also capable of inducing epithelial cells to produce RegIII $\alpha$, which bonds bacterial peptidoglycan carbohydrates and kills targeted Gram-positive bacteria [30]. The microbiome produces metabolites, such as butyrate and tryptophan decomposition metabolites that are able to enhance gut integrity and stimulate innate lymphoid cells group 3 (ILC3) to produce IL-22 [9]. Intraepithelial lymphocytes (IELs), which consist of $\alpha \beta^{+}$and $\gamma \delta^{+} T$ cell populations, play an important role in defense and pathogenesis during inflammation. When IELs are activated, they express cytokines, such as IFN- $\gamma$ and keratinocyte growth factor, to protect epithelial cells from injury [31-33]. The level of IFN- $\gamma$, which is produced by IELs, is closely linked to IBD [34]. Dendritic cells (DCs) are responsible for the immune system's ability to effectively recognize and eliminate exogenous pathogens. DCs have the ability to continuously pass antigens through the barrier to mucosal-associated lymphoid tissue or to drain lymph nodes [35]. Additionally, DCs open the tight junction between the intestinal epithelium and directly enter the lumen to phagocytose Salmonella and E. coli [35]. At the steady state, DCs regulate intestinal immune tolerance by promoting the differentiation of $\mathrm{CD}_{4}{ }^{+} \mathrm{T}$ cells toward regulatory T cells (Tregs) [36] and activating the Tregs through the non-classical autophagy pathway [37]. Sierro et al. [38] further confirmed that the Salmonella flagella protein specifically induced the up-regulated expression of CCL20 and led to DC migration. Pro-inflammatory T helper (Th) cells play an important role in autoimmunity by eliminating pathogens during the host defense reaction and inducing tissue inflammation, which leads to subsequent tissue destruction. Tregs is a major regulatory component in immune tolerance and inflammation. Therefore, the dysregulation of Tregs and pro-inflammatory Th cells in the gut are closely associated with intestinal autoimmunity, such as in IBD [36]. In addition, secretory cells in the epithelial cell layer can synthesize and secrete proteoglycans to form mucus and other cells involved in auxiliary microbial defense [11]. Epithelial cells also express various pattern recognition receptors (PRRs), including Toll-like receptors (TLRs) and nucleotide-binding oligomerization domain-containing protein 2 (NOD2), which also produce chemokines for bone marrow cells and lymphocytes upon anti-inflammatory stimuli [39-41]. TLRs are a group of important PRRs play a vital role in the innate immune system [40]. Microbes can recognize immune regulators, such as chemokines, pro- 
inflammatory cytokines and anti-inflammatory cytokines, through PRR, and these regulators play important roles in autoimmunity and adaptive immunity.

The lamina propria, which consists of $\mathrm{B}$ and $\mathrm{T}$ cells, resides in the lower layer of intestinal epithelial cells. $T$ cells quickly respond to the signal from the lumen environment and initiate inflammatory and anti-inflammatory responses. The intestinal microbiome promoted the differentiation of naive $\mathrm{CD}^{+} \mathrm{T}$ cells toward $\mathrm{CD}^{+} \mathrm{T}$ cells [42]. The lamina propria $\mathrm{CD}_{4}^{+} \mathrm{T}$ cells secreted $\mathrm{IL}-17$ and IL-22, which were involved in regulating intestinal inflammation [43]. Intestinal epithelial cells produce IL17, which can induce the expression of chemokines, such as CXC and CC chemokines [44]. Peyer's patches, the location for IgA-producing $\mathrm{B}$ cell maturation, are distributed along the small intestine with counts of 100 200 in humans and 6-12 in mice [45]. These patches contribute to generating $\mathrm{B}$ cells and plasma cells. Activated $\mathrm{B}$ cells in Peyer's patches consistently generate IgA-producing plasma cells for $\mathrm{T}$ cell-dependent and $\mathrm{T}$ cell-independent responses in the gut $[46,47]$. Secreting IgA is their major contribution to protecting the gut barrier [48]. After activation, $T$ cells and $B$ cells return to the lamina propria, functioning as part of the specific immune response [11]. Intestinal microfold $(M)$ cells are epithelial cells that are primarily present in Peyer's patches of the small intestine and shuttle antigens into the Peyer's patch for appropriate immune responses. Most recently, Sialic acid-binding immunoglobulin-like lectin F (Siglec-F) expression was identified on mouse M cells in the small intestine; Siglec-F functions in antigen transportation in the gut [49].

\section{Gut microbiome and mucosal immunity}

Over the course of evolution, the microbiome maintains symbiosis with the gut environment. The human gut provides nutrients and a breeding environment for intestinal microflora; in turn, intestinal microflora assists in carbohydrate fermentation and synthesize vitamins by reducing intestinal permeability and increasing the epithelial defense mechanism to form a mucosal barrier [50]. The intestinal mucosal immune system constitutes the largest immune component in vertebrates, functioning closely with the intestinal microbiome. The balance of the intestinal mucosa immune system plays a key role in host homeostasis and defense. Studies on GF mice suggested that the intestinal microbiome plays a vital role in the formation of mucosal immunity. Compared with specific pathogen free (SPF) animals, GF animals produce fewer IELs [51] and have significantly reduced IgA-secreting plasma cells in the lamina propria [52], as well as fewer Tregs [53]. Angiogenin-4 (Ang4) is a class of microbicidal proteins in Paneth cells and can be secreted into the gut lumen against microbes. Real-time quantitative RT-PCR suggested that the mRNA expression level of Ang4 markedly decreased in GF mice compared with conventional mice [54]. This result indicates that gut microbiota is required for mucosal immunity. Additionally, Peyer's patches in GF mice contain a smaller germinal center than in conventional mice [9]. The intestinal mucosa is the main site for microbiomehost interactions. A recent study showed that IgA in the feces significantly increased after treatment with prebiotics, while the expression of pro-inflammatory factor in the mesenteric lymph nodes and Peyer's patches was significantly reduced. Additionally, the IL-10, CXCL-1 and Mucin- 6 genes were up-regulated, while the colonic mu$\operatorname{cosa} 4$, IFN- $\gamma$, GM-CSF and IL- $1 \beta$ genes were downregulated in the ileum [48]. These results indicated that the gut microbiome affect intestinal mucosal immune balance.

The dynamic interaction between the microbiome and environmental factors shapes mucosal and systemic immunity. Diet and exogenous substrates are the key regulatory factors of the intestinal microbiome. In obese subjects, the ratio of Bacteroidetes/Firmicutes was reported to be decreased [55]. High fat and high sugar diet feeding changed the composition and diversity of the gut microbiome in mice, leading to altered SCFA production [56]. In healthy individuals, the microbiome primarily consists of 4 groups of bacteria: Firmicutes, Bacteroidetes, Proteobacteria and Actinobacteria [57].

Carasi et al. [48] found that LPS induced a significant decline in the production of IL-6 and GM-CSF in Lactobacillus kefiri-treated mice, indicating that Lactobacillus kefiri is an important factor of intestinal inflammatory dysbiosis. Bacteroides fragilis, a type of symbiotic bacteria, can produce polysaccharide A with antiinflammatory effects by inhibiting IL-17 production and enhancing the activity of intestinal Tregs $[58,59]$. Polysaccharide A regulates $\mathrm{CD}^{+} \mathrm{T}$ cell transformation toward Foxp $3^{+}$Tregs in a TLR2-dependent manner [59]. Subsequently, Tregs produce anti-inflammatory IL-10 in response to defend inflammatory injuries [59, 60]. The colonization of Clostridium clusters IV and XIVa in the large intestine enhance the level of TGF- $\beta_{1}$ and promote IL-10-expressed Foxp3 ${ }^{+}$Tregs [61, 62]. However, Clostridium clusters IV and XIVa declined in IBD. An analysis of dsDNA virus-like particles in IBD patients suggested that the Caudovirales bacteriophages remarkably expanded, and this expansion was associated with a significant alteration of bacteria [63]. Hence, the complex interaction between the microbiome and its host maintains a spatial separation of the microbiome and intestinal epithelial cells, which promotes host homeostasis. The effect of segmented filamentous bacteria (SFB) on promoting the Th17 response has drawn substantial attention. SFB are closely related to intestinal 
inflammation $[64,65]$. The colonization of SFB promoted systemic Th17 cell activation and triggered arthritis in $\mathrm{GF} \mathrm{K} / \mathrm{BxN}$ mice [66], as well as accelerated experimental autoimmune encephalomyelitis [67].

\section{The dysbiosis of the gut microbiome induces intestinal diseases}

The intestinal microbiota and mucosal immunity constantly interact to achieve intestinal homeostasis. However, once the balance is broken, dysfunction of the intestinal immune system will trigger a variety of diseases, such as IBD. IBD is a heterogeneous disease influenced by genetic, environmental and microbial factors, leading to intestinal inflammation by triggering an abnormal immune response. Crohn's disease (CD) and ulcerative colitis (UC) are typical IBDs [50]. Studies have shown that genetic susceptibility was not sufficient to trigger IBD, the concordance of which was only $35 \%$ for $\mathrm{CD}$ and $16 \%$ for UC in monozygotic twins [68]. This result indicated that in addition to genetic factors, environmental and microbial factors are also important for IBD pathogenesis. Studies have shown that intestinal dysbiosis led to an abnormal adaptive immune response that increased IBD inflammation and the destruction of the gastrointestinal tract $[69,70]$. The rapid development of next generation sequencing technology has provided further information on the human genome and the composition of the intestinal microflora genome, and it has aided in the determination of which species of intestinal microorganisms are related to disease development $[2,37]$. Therefore, intestinal microflora manipulation has been a powerful preventive and therapeutic intervention against inflammation. Among these, fecal microbiota transplantation is an effective treatment for IBD [71]. Recent studies have shown that one of the important genes for regulating the pathogenesis of IBD, Caspase recruitment domain family member 9 (CARD9), was responsible for mediating intracellular signals to trigger inflammation. The intestinal microbial structure was altered and susceptible to intestinal fungus infection in CARD9 knockout mice, indicating that the deletion of CARD9 led to IBD dysbiosis [72]. In patients with mild to moderate colitis, the production of IL-22 by ILC3 was elevated when exposed to excreta, suggesting the involvement of gut microbiota [73]. Additional studies have also found a relationship between the abnormal expression of miRNA and the development of IBD. MiR$19 \mathrm{~b}$ expression was found to be significantly reduced in CD [74]. Bioinformatics analysis showed that a suppressor of cytokine signaling (SOCS3) was considered the possible target of miR-19b. By inhibiting SOCS3, MiR$19 \mathrm{~b}$ regulates intestinal epithelial cells to produce cytokines, thereby inhibiting the inflammatory response and eventually preventing the onset of $\mathrm{CD}$ [74].
Altered microbiota diversity was found in IBD, and it was reflected by a decline in commensal bacteria, such as Firmicutes and Bacteroidetes, and an increase in detrimental bacteria, such as Proteobacteria and Actinobacteria [17]. Due to the decreased microbial diversity in IBD, the ability of microbiota to adapt to environmental changes and to defend against natural disturbances is impaired. Active bacterial products can regulate the inflammatory response in IBD. For example, IL-10 deficiency was found to be associated with early-onset IBD $[75,76]$. SCFAs are dietary fiber produced by gut bacteria fermentation. Studies of fecal samples from IBD patients showed that SCFA levels were remarkably changed, supporting the important role of SCFAs in IBD [77]. SCFAs regulate certain inflammatory responses by binding GPR43 [78]. Additionally, SCFAs regulate colonic Treg cell homeostasis by restoring the colonic size and function of the Treg cell pool in GF mice [79].

Gut microbiota produce many immunogenicity substances. For example, complex lipopolysaccharides on the cell surface of Gram-negative bacteria caused a fecal immune response. In some cases, immunogenic substances pass through the intestinal wall, especially when the barrier is destroyed, causing further damage [80]. Bacteroides fragilis found in the human intestine plays a positive regulatory role in the human immune system. In GF mice, Bacteroides fragilis promoted the Foxp $3^{+} \mathrm{T}$ cells to produce anti-inflammatory cytokines in the gut [59]. Recent studies showed that intestinal microflora enveloped with IgA from IBD patients promoted the sensibility of dextran sodium sulfate-induced colitis in GF mice. Intestinal microflora, especially enterobacterium, promoted host IgA effects [81]. These studies highlight the complex interactions between intestinal microflora and IgA in the pathogenesis of intestinal inflammation.

\section{Effects of gut microbiome and mucosal immunity in autoimmune diseases}

The pathogenetic mechanism of systemic autoimmune diseases remains unclear; genetic and environmental factors may have certain effects. A gut microbiome challenge may initiate autoimmune diseases. Studies have shown that some autoantibodies, such as antinuclear antibodies, anti-double-stranded DNA in systemic lupus erythematosus (SLE), and rheumatoid factor, anticitrullinated protein antibodies (ACPAs) in rheumatoid arthritis (RA) could be detected before the onset, indicating that the microbiome plays an important role in the development of autoimmune diseases, especially Porphyromonas gingivalis (P.gingivalis) [82-84]. Hevia et al. [85] recently found that the ratio of gut Firmicutes/Bacteroidetes decreased in SLE patients, indicating that the dysfunction of mucosal immunity in SLE patients may influence the gut microbiome community. Similarly, $P$. 
gingivalis was shown to be the potential initiator, causing RA to form ACPAs [84]. Recent studies have shown a close relationship between microbiota and RA, including Mycoplasma [86], Proteus [87], Escherichia [88], Haemophilusspp, Lactobacillussalivarius, etc. [89]. 16S rRNA analysis showed that Lactobacillus significantly increased in the fecal microbiota of RA patients compared to the control [90]. Compared to RA patients with long-term treatment, an increase in Prevotella and a decline in Bacteroides were found in early RA patients [91], indicating the influence of Prevotellain RA disease development. The functional analysis of Prevotella-dominating metagenomics showed that the purine metabolic pathways significantly declined, which may have affected the therapeutic efficiency of methotrexate in RA [91]. Studies also showed that the microbial components in the terminal ileum significantly changed in ankylosing spondylitis (AS); the abundance of five bacterial species significantly increased, including Lachnospiraceae, Ruminococcaceae, Rikenellaceae, Porphyromonadaceae and Bacteroidaceae. Conversely, Veillonellaceae and Prevotellaceae declined [92]. Hence, the dysbiosis of gut microbiota is closely associated with autoimmune diseases.

\section{Conclusions}

In summary, intestinal microbiota coordinates to shape host immunity and contribute to maintaining intestinal homeostasis and inhibiting inflammation. Recent data have shown the pivotal role of intestinal microbiota in mucosal immunity. An impaired interaction between intestinal microbiota and mucosal immune system is associated with the pathogenesis of inflammatory diseases, such as IBD, RA, SLE, AS, etc., and it highlights the importance of exploring the function of microbiota in such diseases. Thus, intestinal microbiota has become effective targets for the development of new diagnostic methods. Balancing the gut microbiome will likely represent an effective treatment for chronic inflammatory diseases.

\begin{abstract}
Abbreviations
ACPAs: Anti-citrullinated protein antibodies; AMP: Antimicrobial peptides; Ang4: Angiogenin-4; AS: Ankylosing spondylitis; CARD9: Caspase recruitment domain family member 9; CD: Crohn's disease; DC: Dendritic cell; GF: Germfree; IBD: Inflammatory bowel disease; IEL: Intraepithelial lymphocyte; ILC: Innate lymphoid cell; NEC: Necrotizing enterocolitis; NOD2: Nucleotidebinding oligomerization domain-containing protein 2;

P.gingivalis: Porphyromonas gingivalis; PRR: Pattern recognition receptor; RA: Rheumatoid arthritis; SCFA: Short chain fatty acid; SFB: Segmented filamentous bacterium; Siglec-F: Sialic acid-binding immunoglobulin-like lectin F; SLE: Systemic lupus erythematosus; SOCS3: Suppressor of cytokine signaling; SPF: Specific pathogen free; Th: T helper; TLR: Toll-like receptors; Treg: Regulatory T cell; UC: Ulcerative colitis
\end{abstract}

\section{Funding}

"PUMC" Fellow award from Peking Union Medical Collage (PUMC) CAMS Initiative for Innovative Medicine (2016-I2M-1-006).
Availability of data and materials

Not applicable.

\section{Authors' contributions}

NS and NL performed the literature search and wrote the main body of the manuscript. XD provided critical writing in the revised manuscript. HN designed and instructed the writing of the manuscript. All authors read and approved the final manuscript.

\section{Competing interests}

The authors declare that they have no competing interests.

\section{Consent for publication}

Not applicable.

\section{Ethics approval and consent to participate}

Not applicable.

\section{Author details}

${ }^{1}$ Institute of Laboratory Animal Sciences, Chinese Academy of Medical Sciences (CAMS) and Comparative Medicine Center, Peking Union Medical Collage (PUMC), Key Laboratory of Human Disease Comparative Medicine, Ministry of Health, Beijing 100021, China. ${ }^{2}$ Department of Rheumatology, the Second Affiliated Hospital of Nanchang University, Nanchang 330006, China.

Received: 18 October 2016 Accepted: 10 April 2017

Published online: 27 April 2017

\section{References}

1. Qin J, Li R, Raes J, Arumugam M, Burgdorf KS, Manichanh C, et al. A human gut microbial gene catalogue established by metagenomic sequencing. Nature. 2010;464:59-65.

2. Eckburg PB, Bik EM, Bernstein CN, Purdom E, Dethlefsen L, Sargent M, et al. Diversity of the human intestinal microbial flora. Science. 2005;308:1635-8.

3. Lee YK, Mazmanian SK. Has the microbiota played a critical role in the evolution of the adaptive immune system? Science. 2010;330:1768-73.

4. Harmsen $\mathrm{H}$, de Goffau M. The human gut microbiota. Adv Exp Med Biol. 2016;902:95-108.

5. Hasegawa M, Inohara N. Regulation of the gut microbiota by the mucosal immune system in mice. Int Immunol. 2014;26:481-7.

6. Richards JL, Yap YA, Mcleod KH, Mackay CR, Marino E. Dietary metabolites and the gut microbiota: an alternative approach to control inflammatory and autoimmune diseases. Clin Transl Immunol. 2016;5:e82.

7. Chan CW, Wong RS, Law PT, Wong CL, Tsui SK, Tang WP, et al. Environmental factors associated with altered gut microbiota in children with eczema: a systematic review. Int J Mol Sci. 2016;17:1147.

8. Kau AL, Ahern PP, Griffin NW, Goodman AL, Gordon Jl. Human nutrition, the gut microbiome and the immune system. Nature. 2011;474:327-36.

9. Mcdermott AJ, Huffnagle GB. The microbiome and regulation of mucosal immunity. Immunology. 2014;142:24-31.

10. Topping DL, Clifton PM. Short-chain fatty acids and human colonic function: roles of resistant starch and nonstarch polysaccharides. Physiol Rev. 2001;81: 1031-64.

11. Kuhn KA, Pedraza I, Demoruelle MK. Mucosal immune responses to microbiota in the development of autoimmune disease. Rheum Dis Clin N Am. 2014;40:711-25

12. Romanokeeler J, Moore DJ, Wang C, Brucker RM, Fonnesbeck C. Early life establishment of site-specific microbial communities in the gut. Gut Microbes. 2014:5:192-201.

13. Turnbaugh PJ, Ley RE, Mahowald MA, Magrini V, Mardis ER, Gordon JI. An obesity-associated gut microbiome with increased capacity for energy harvest. Nature. 2006;444:1027-131.

14. Qin J, Li Y, Cai Z, Li S, Zhu J, Zhang F, et al. A metagenome-wide association study of gut microbiota in type 2 diabetes. Nature. 2012; 490:55-60.

15. Yang T, Santisteban MM, Rodriguez V, Li E, Ahmari N, Carvajal JM, et al. Gut dysbiosis is linked to hypertensionnovelty and significance. Hypertension. 2015:65:1331-40.

16. Mai V, Young CM, Ukhanova M, Wang X, Sun Y, Casella G, et al. Fecal microbiota in premature infants prior to necrotizing enterocolitis. PLOS ONE. 2011;6:e20647. 
17. Frank DN, St AA, Feldman RA, Boedeker EC, Harpaz N, Pace NR. Molecularphylogenetic characterization of microbial community imbalances in human inflammatory bowel diseases. Proc Natl Acad Sci U S A. 2007;104: 13780-5.

18. Ayabe T, Ashida T, Kohgo Y, Kono T. The role of paneth cells and their antimicrobial peptides in innate host defense. Trends Microbiol. 2004;12: 394-8.

19. van Es JH, Jay $P$, Gregorieff A, Van Gijn ME, Jonkheer S, Hatzis $P$, et al. Wnt signalling induces maturation of paneth cells in intestinal crypts. Nat Cell Biol. 2005;7:381-6.

20. Bals R, Weiner DJ, Moscioni AD, Meegalla RL, Wilson JM. Augmentation of innate host defense by expression of a cathelicidin antimicrobial peptide. Infect Immunol. 1999:67:6084-9.

21. Scott MG, Davidson DJ, Gold MR, Bowdish D, Hancock RE. The human antimicrobial peptide IL-37 is a multifunctional modulator of innate immune responses. J Immunol. 2002;169:3883-91.

22. Wilson CL, Ouellette AJ, Satchell DP, Ayabe T, Lopez-Boado YS, Stratman JL, et al. Regulation of intestinal alpha-defensin activation by the metalloproteinase matrilysin in innate host defense. Science. 1999;286:113-7.

23. Cash HL, Whitham CV, Behrendt CL, Hooper LV. Symbiotic bacteria direct expression of an intestinal bactericidal lectin. Science. 2006:313:1126-30.

24. Ayabe T, Satchell DP, Wilson CL, Parks WC, Selsted ME, Ouellette AJ. Secretion of microbicidal alpha-defensins by intestinal paneth cells in response to bacteria. Nat Immunol. 2000;1:113-8.

25. Birchler T, Seibl R, Buchner K, Loeliger S, Seger R, Hossle JP, et al. Human Toll-like receptor 2 mediates induction of the antimicrobial peptide human beta-defensin 2 in response to bacterial lipoprotein. Eur J Immunol. 2001;31: 3131-7

26. Stelter C, Kappeli R, Konig C, Krah A, Hardt WD, Stecher B, et al. Salmonellainduced mucosal lectin regiiibeta kills competing gut microbiota. PLOS ONE. 2011;6:E20749

27. Vaishnava S, Yamamoto M, Severson KM, Ruhn KA, Yu X, Koren O, et al. The Antibacterial lectin Reglll promotes the spatial segregation of microbiota and host in the intestine. Science. 2011;334:255-8.

28. Zenewicz LA, Yancopoulos GD, Valenzuela DM, Murphy AJ, Stevens S, Flavell RA. Innate and adaptive interleukin-22 protects mice from inflammatory bowel disease. Immunity. 2008;29:947-57.

29. Sonnenberg GF, Monticelli LA, Elloso MM, Fouser LA, Artis D. CD4(+) lymphoid tissue-inducer cells promote innate immunity in the gut. Immunity. 2011;34:122-34.

30. Mukherjee S, Zheng H, Derebe MG, Callenberg KM, Partch CL, Rollins D, et al. Antibacterial membrane attack by a pore-forming intestinal c-type lectin. Nature. 2014:505:103-7.

31. Wang $\mathrm{HC}$, Zhou Q, Dragoo J, Klein JR. Most murine $\mathrm{CD}^{+}$intestinal intraepithelial lymphocytes are partially but not fully activated t cells. J Immunol. 2002;169:4717-22.

32. Moretto $M$, Weiss $L M$, Khan IA. Induction of a rapid and strong antigenspecific intraepithelial lymphocyte response during oral Encephalitozoon cuniculi infection. J Immunol. 2004;172:4402-9.

33. Boismenu R, Havran WL. Modulation of epithelial cell growth by intraepithelial gamma delta T cells. Science. 1994;266:1253-5.

34. Simpson SJ, Hollander GA, Mizoguchi E, Allen D, Bhan AK, Wang B, et al. Expression of pro-inflammatory cytokines by TCR alpha beta + and TCR gamma delta $+\mathrm{T}$ cells in an experimental model of colitis. Eur J Immunol. 1997;27:17-25

35. Rescigno $M$, Urbano $M$, Valzasina $B$, Francolini $M$, Rotta $G$, Bonasio $R$, et al. Dendritic cells express tight junction proteins and penetrate gut epithelial monolayers to sample bacteria. Nat Immunol. 2001;2:361-7.

36. Colombo BM, Scalvenzi T, Benlamara S, Pollet N. Microbiota and mucosal immunity in amphibians. Front Immunol. 2015;6:111.

37. Chu H, Khosravi A, Kusumawardhani IP, Kwon AH, Vasconcelos AC, Cunha $L D$, et al. Gene-microbiota interactions contribute to the pathogenesis of inflammatory bowel disease. Science. 2016;352:1116-20.

38. Sierro F, Dubois B, Coste A, Kaiserlian D, Kraehenbuhl JP, Sirard JC. Flagellin stimulation of intestinal epithelial cells triggers CCL20-mediated migration of dendritic cells. Proc Natl Acad Sci U S A. 2001;98:13722-7.

39. Gewirtz AT, Navas TA, Lyons S, Godowski PJ, Madara JL. Cutting edge: bacterial flagellin activates basolaterally expressed TLR5 to induce epithelial proinflammatory gene expression. J Immunol. 2001;167:1882-5.

40. Akira S, Takeda K, Kaisho T. Toll-like receptors: critical proteins linking innate and acquired immunity. Nat Immunol. 2001;2:675-80.
41. Hayashi F, Smith KD, Ozinsky A, Hawn TR, Yi EC, Goodlett DR, et al. The innate immune response to bacterial flagellin is mediated by Toll-like receptor 5. Nature. 2001;410:1099-103.

42. Lui JB, Devarajan P, Teplicki SA, Chen Z. Cross-differentiation from the CD8 lineage to cd4 t cells in the gut-associated microenvironment with a nonessential role of microbiota. Cell Rep. 2015;10:574-85.

43. Munoz M, Heimesaat MM, Danker K, Struck D, Lohmann U, Plickert R, et al. Interleukin (IL)-23 mediates toxoplasma gondii-induced immunopathology in the gut via matrixmetalloproteinase-2 and IL-22 but independent of IL17. J Exp Med. 2009:206:3047-59.

44. Awane M, Andres PG, Li DJ, Reinecker HE. NF-kappa B-inducing kinase is a common mediator of IL-17, TNF-alpha, and IL-1 beta-induced chemokine promoter activation in intestinal epithelial cells. J Immunol. 1999;162:5337-44.

45. Reboldi A, Cyster JG. Peyer's patches: organizing B-cell responses at the intestinal frontier. Immunol Rev. 2016:271:230-45.

46. Bemark M, Boysen $P$, Lycke NY. Induction of gut IgA production through $T$ cell-dependent and T cell-independent pathways. Ann N Y Acad Sci. 2012; 1247:97-116.

47. Bergqvist P, Stensson A, Lycke NY, Bemark M. T cell-independent IgA class switch recombination is restricted to the galt and occurs prior to manifest germinal center formation. J Immunol. 2010;184:3545-53.

48. Carasi P, Racedo SM, Jacquot C, Romanin DE, Serradell MA, Urdaci MC. Impact of kefir derived lactobacillus kefiri on the mucosal immune response and gut microbiota. J Immunol Res. 2015;2015:1-12.

49. Gicheva N, Macauley MS, Arlian BM, Paulson JC, Kawasaki N. Siglec-F is a novel intestinal M cell marker. Biochem Biophys Res Commun. 2016;479:1-4.

50. Berg D, Clemente JC, Colombel JF. Can inflammatory bowel disease be permanently treated with short-term interventions on the microbiome? Expert Rev Gastroenterol Hepatol. 2015;9:781-95.

51. Bandeira A, Mota-Santos T, Itohara S, Degermann S, Heusser C, Tonegawa S, et al. Localization of gamma/delta T cells to the intestinal epithelium is independent of normal microbial colonization. J Exp Med. 1990;172:239-44.

52. Crabbe PA, Bazin H, Eyssen $H$, Heremans JF. The normal microbial flora as a major stimulus for proliferation of plasma cells synthesizing lga in the gut. the germ-free intestinal tract. Int Arch Allergy Appl Immunol. 1968:34:362-75.

53. Ostman S, Rask C, Wold AE, Hultkrantz S, Telemo E. Impaired regulatory T cell function in germ-free mice. Eur J Immunol. 2006:36:2336-46.

54. Hooper LV, Stappenbeck TS, Hong CV, Gordon Jl. Angiogenins: a new class of microbicidal proteins involved in innate immunity. Nat Immunol. 2003;4: 269-73.

55. Ley RE, Turnbaugh PJ, Klein S, Gordon Jl. Microbial ecology: human gut microbes associated with obesity. Nature. 2006:444:1022-3.

56. David LA, Maurice CF, Carmody RN, Gootenberg DB, Button JE, Wolfe BE, et al. Diet rapidly and reproducibly alters the human gut microbiome. Nature. 2014;505:559-63.

57. Wright EK, Kamm MA, Teo SM, Inouye M, Wagner J, Kirkwood CD. Recent advances in characterizing the gastrointestinal microbiome in crohn's disease. Inflamm Bowel Dis. 2015;21:1219-28.

58. Sk M, Round JL, Kasper DL. A microbial symbiosis factor prevents intestinal inflammatory disease. Nature. 2008;453:620-5.

59. Round JL, Mazmanian SK. Inducible Foxp3 $3^{+}$regulatory T-cell development by a commensal bacterium of the intestinal microbiota. Proc Natl Acad Sc U S A. 2010;107:12204-9.

60. Round JL, Lee SM, Li J, Tran G, Jabri B, Chatila TA, et al. The Toll-like receptor 2 pathway establishes colonization by a commensal of the human microbiota. Science. 2011;332:974-7.

61. Atarashi K, Tanoue T, Shima T, Imaoka A, Kuwahara T, Momose Y, et al. Induction of colonic regulatory $T$ cells by indigenous clostridium species. Science. 2011:331:337-41.

62. Atarashi K, Tanoue T, Oshima K, Suda W, Nagano Y, Nishikawa H, et al. Treg induction by a rationally selected mixture of clostridia strains from the human microbiota. Nature. 2013;500:232-6.

63. Norman JM, Handley SA, Baldridge MT, Droit L, Liu CY, Keller BC, et al. Disease-specific alterations in the enteric virome in inflammatory bowel disease. Cell. 2015;160:447-60.

64. Ivanov II, Atarashi K, Manel N, Brodie EL, Shima T, Karaoz U, et al. Induction of intestinal Th17 cells by segmented filamentous bacteria. Cell. 2009;139: 485-98.

65. Stepankova R, Powrie F, Kofronova O, Kozakova H, Hudcovic T, Hrncir T, et al. Segmented filamentous bacteria in a defined bacterial cocktail induce 
intestinal inflammation in SCID mice reconstituted with CD45RB high CD4 ${ }^{+}$ T cells. Inflamm Bowel Dis. 2007:13:1202-11.

66. Ivanov II WHJ, Darce J, Hattori K, Shima T, Umesaki Y, et al. Gut-residing segmented filamentous bacteria drive autoimmune arthritis via T helper 17 cells. Immunity. 2010;32:815-27.

67. Lee YK, Menezes JS, Umesaki Y, Mazmanian SK. Proinflammatory T-cell responses to gut microbiota promote experimental autoimmune encephalomyelitis. Proc Natl Acad Sci U S A. 2011;108:4615-22.

68. Spehlmann ME, Begun AZ, Burghardt J, Lepage P, Raedler A, Schreiber S. Epidemiology of inflammatory bowel disease in a german twin cohort: results of a nationwide study. Inflamm Bowel Dis. 2008;14:968-76.

69. Seksik P, Rigottier-Gois L, Gramet G, Sutren M, Pochart P, Marteau P, et al. Alterations of the dominant faecal bacterial groups in patients with crohn's disease of the colon. Gut. 2003;52:237-42.

70. Gophna U, Sommerfeld K, Gophna S, Doolittle WF, Veldhuyzen VZS Differences between tissue-associated intestinal microfloras of patients with Crohn's disease and ulcerative colitis. J Clin Microbiol. 2006:44:4136-41.

71. Wang ZK, Yang YS, Chen Y, Yuan J, Sun G, Peng LH. Intestinal microbiota pathogenesis and fecal microbiota transplantation for inflammatory bowel disease. World J Gastroenterol. 2014;20:14805-20.

72. Lamas B, Richard ML, Leducq V, Pham HP, Michel ML, Da CG, et al. CARDg impacts colitis by altering gut microbiota metabolism of tryptophan into aryl hydrocarbon receptor ligands. Nat Med. 2016;22:598-605.

73. Longman RS, Diehl GE, Victorio DA, Huh JR, Galan C, Miraldi ER, et al. CX(3)CR1(+) mononuclear phagocytes support colitis-associated innate lymphoid cell production of IL-22. J Exp Med. 2014;211:1571-83.

74. Cheng X, Zhang X, Su J, Zhang Y, Zhou W, Zhou J, et al. Mir-19b downregulates intestinal SOCS3 to reduce intestinal inflammation in Crohn's disease. Sci Rep. 2015:5:10397.

75. Glocker EO, Kotlarz D, Boztug K, Gertz EM, Schaffer AA, Noyan F, et al. Inflammatory bowel disease and mutations affecting the interleukin-10 receptor. N Engl J Med. 2009;361:2033-45.

76. Shah N, Kammermeier J, Elawad M, Glocker EO. Interleukin-10 and interleukin-10-receptor defects in inflammatory bowel disease. Curr Allergy Asthma Rep. 2012;12:373-9.

77. Huda-Faujan N, Abdulamir AS, Fatimah AB, Anas OM, Shuhaimi M, Yazid $\mathrm{AM}$, et al. The impact of the level of the intestinal short chain fatty acids in inflammatory bowel disease patients versus healthy subjects. Open Biochem J. 2010:4:53-8.

78. Maslowski KM, Vieira AT, Ng A, Kranich J, Sierro F, Yu D, et al. Regulation of inflammatory responses by gut microbiota and chemoattractant receptor GPR43. Nature. 2009:461:1282-6.

79. Smith PM, Howitt MR, Panikov N, Michaud M, Gallini CA, Bohlooly YM, et al. The microbial metabolites, short-chain fatty acids, regulate colonic Treg cell homeostasis. Science. 2013;341:569-73.

80. Macfarlane GT, Blackett KL, Nakayama T, Steed H, Macfarlane S. The gut microbiota in inflammatory bowel disease. Curr Pharm Design. 2009;15: 1528-36.

81. Palm NW, de Zoete MR, Cullen TW, Barry NA, Stefanowski J, Hao L, et al. Immunoglobulin A coating identifies colitogenic bacteria in inflammatory bowel disease. Cell. 2014;158:1000-10.

82. Rantapaa-Dahlqvist S, de Jong BA, Berglin E, Hallmans G, Wadell G, Stenlund $\mathrm{H}$, et al. Antibodies against cyclic citrullinated peptide and IgA rheumatoid factor predict the development of rheumatoid arthritis. Arthritis Rheum. 2003:48:2741-9.

83. Arbuckle MR, Mcclain MT, Rubertone MV, Scofield RH, Dennis GJ, James JA, et al. Development of autoantibodies before the clinical onset of systemic lupus erythematosus. N Engl J Med. 2003;349:1526-33.

84. Mikuls TR, Thiele GM, Deane KD, Payne JB, O'dell JR, Yu F, et al. Porphyromonas gingivalis and disease-related autoantibodies in individuals at increased risk of rheumatoid arthritis. Arthritis Rheum. 2012;64:3522-30.

85. Hevia A, Milani C, Lopez P, Cuervo A, Arboleya S, Duranti S, et al. Intestinal dysbiosis associated with systemic lupus erythematosus. MBio. 2014;5: E01548-14.

86. Ramirez AS, Rosas A, Hernandez-Beriain JA, Orengo JC, Saavedra P, de la Fe C, et al. Relationship between rheumatoid arthritis and mycoplasma pneumoniae: a case-control study. Rheumatology (Oxford). 2005;44:912-4.

87. Rashid T, Ebringer A. Rheumatoid arthritis is linked to proteus-the evidence. Clin Rheumatol. 2007;26:1036-43.
88. Syrbe U, Scheer R, Wu P, Sieper J. Differential synovial Th1 cell reactivity towards escherichia coli antigens in patients with ankylosing spondylitis and rheumatoid arthritis. Ann Rheum Dis. 2012;71:1573-6.

89. Zhang $X$, Zhang D, Jia H, Feng Q, Wang D, Liang D, et al. The oral and gut microbiomes are perturbed in rheumatoid arthritis and partly normalized after treatment. Nat Med. 2015;21:895-905.

90. Liu X, Zou Q, Zeng B, Fang Y, Wei H. Analysis of fecal lactobacillus community structure in patients with early rheumatoid arthritis. Curr Microbiol. 2013;67:170-6.

91. Scher JU, Sczesnak A, Longman RS, Segata N, Ubeda C, Bielski C, et al. Expansion of intestinal prevotella copri correlates with enhanced susceptibility to arthritis. Elife. 2013;2:E01202.

92. Costello M, Ciccia F, Willner D, Warrington N, Robinson PC, Gardiner B, et al. Intestinal dysbiosis in ankylosing spondylitis. Arthritis Rheumatol. 2015;67: 686-91.

\section{Submit your next manuscript to BioMed Central and we will help you at every step:}

- We accept pre-submission inquiries

- Our selector tool helps you to find the most relevant journal

- We provide round the clock customer support

- Convenient online submission

- Thorough peer review

- Inclusion in PubMed and all major indexing services

- Maximum visibility for your research

Submit your manuscript at www.biomedcentral.com/submit

) Biomed Central 